\title{
Diagnosis and treatment of limb-girdle and distal dystrophies
}

\section{Payment policy perspectives}

\author{
Raghav Govindarajan, MD \\ Katie M. Shepard \\ Lyell K. Jones Jr, MD
}

\begin{abstract}
Limb-girdle muscular dystrophies (LGMDs) and distal dystrophies are a diverse group of genetically heterogeneous myopathies characterized by an evolving and often confusing nomenclature. Though rare as a group, they are commonly seen in neuromuscular clinics and occasionally in general neurology clinics, and are frequently a source of diagnostic dilemma. A recent evidence-based guideline by the American Academy of Neurology provides a comprehensive analysis of the clinical phenotypes, diagnostic approach, and management principles of the LGMDs and associated disorders. There remain many unanswered questions regarding the role of radiologic and genetic testing, cardiorespiratory screening, and physical therapy in managing these patients.
\end{abstract}

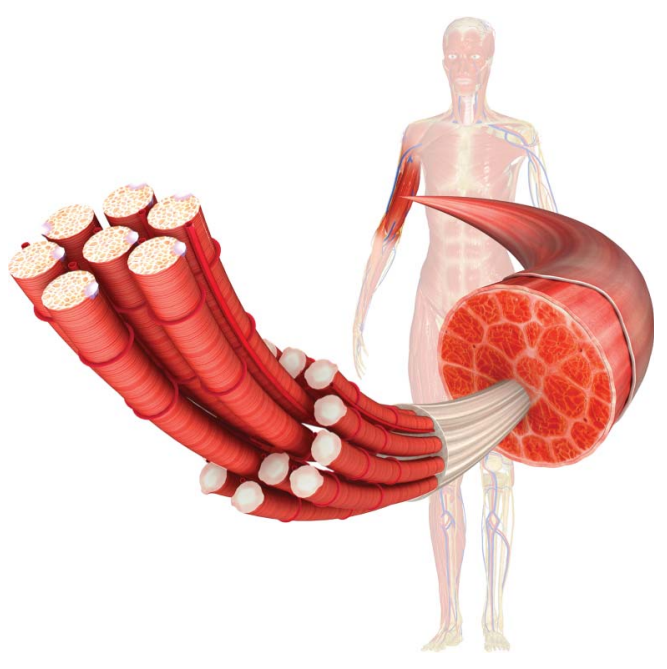

This payment policy article suggests potential solutions to challenging coverage scenarios that result from incomplete or conflicting evidence. Neurol Clin Pract 2015;5:454-459

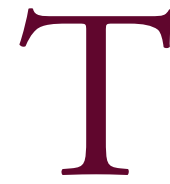

he limb-girdle muscular dystrophies (LGMDs) and distal dystrophies are a diverse group of genetically heterogeneous muscular disorders typically characterized by slowly progressive muscle weakness. New forms of these disorders are identified on an ongoing basis, particularly among the LGMD phenotypes, and the nosology and nomenclature of these disorders is often confusing. ${ }^{1}$ Though LGMDs as a group are rare disorders, they may be commonly seen in subspecialty neuromuscular clinics and occasionally in general neurology clinics, and frequently present a diagnostic challenge.

A recent evidence-based guideline by the American Academy of Neurology (AAN) and American Association of Neuromuscular and Electrodiagnostic Medicine provides a thorough

University of Missouri (RG), Columbia; American Academy of Neurology (KMS), Minneapolis; and Mayo Clinic (LKJ), Rochester, MN.

Funding information and disclosures are provided at the end of the article. Full disclosure form information provided by the authors is available with the full text of this article at Neurology.org/cp.

Correspondence to: kshepard@aan.com 


\section{By aiding in diagnosis, neuromuscular imaging may help avoid unnecessary and potentially costly immunosuppressive medication and may help improve the diagnostic yield of muscle biopsy.}

analysis of the clinical phenotypes, diagnostic approach, and management principles of the LGMDs and associated disorders. ${ }^{1}$ While the guideline provides a comprehensive analysis of the clinical phenotypes and diagnostic approach to various LGMDs, with an overview of management options, there may remain unanswered questions regarding the role of various diagnostic tests and treatment modalities, including radiologic and genetic testing, cardiorespiratory screening, and physical therapy.

Many patients with LGMD and distal dystrophies need long-term multispecialty care, necessitating frequent interaction with patients' third-party payers. Further, our knowledge about various LGMDs and their genetic inheritance patterns are rapidly expanding, resulting in changes in best clinical practice. ${ }^{2}$ Finally, while disease-modifying treatment options remain elusive, establishing a genetic diagnosis prevents the use of needless, potentially harmful, and expensive immunosuppressive therapies. These issues pose further payment challenges, which are discussed in this article.

\section{LGMD nomenclature and ICD coding}

Traditionally LGMDs have been classified as LGMD types 1 or 2 based on their inheritance pattern with numbers indicating Mendelian inheritance pattern (1 autosomal dominant, 2 autosomal recessive) and letters indicating the chronologic order of the discovery of their chromosomal locus. ${ }^{3}$ The discovery of new chromosomal loci and associated phenotypic variability has added to a lengthy and intimidating list that can present diagnostic challenges even to experienced neuromuscular physicians. This complexity can have the potential to create confusion in International Classification of Diseases (ICD) coding (especially among new providers or those who are not experienced in coding for neurologic disease) and thus set stage for denial of services. We suggest using ICD-9 code 359.1 (hereditary progressive muscular dystrophy), which, though limited, still encompasses 10 common muscular dystrophies including LGMD as a group. ${ }^{4}$ Further, with $I C D-10-C M$ looming, we suggest G71.0, which has expanded to include 12 different dystrophies (including LGMDs) and also provides a more comprehensive description of phenotypic variability of these dystrophies. 5

\section{Imaging as a diagnostic tool in LGMD}

While the recent LGMD and distal dystrophies guideline was not specifically designed to provide a level of evidence on the use of imaging in the diagnosis of LGMD, it does conclude that a combination of clinical, radiologic, and laboratory features are useful in directing genetic diagnosis (multiple Class I-III studies) in dystrophic disorders. ${ }^{1}$ Muscle MRIs are increasingly being used to provide clues in diagnosing dystrophies (including LGMD) based on the specific patterns of signal changes in various muscles in different limb compartments. ${ }^{6}$

In certain types of muscular dystrophy (e.g., Becker muscular dystrophy), unique patterns of muscle MRI change may be present even in advanced cases, helping in diagnosis. ${ }^{7}$ By aiding in diagnosis, neuromuscular imaging may help avoid unnecessary and potentially costly immunosuppressive medication and may help improve the diagnostic yield of muscle biopsy. MRI 
has a safety advantage over $\mathrm{CT}$ in that it requires no exposure to ionizing radiation, and MRIs provide better soft tissue discrimination.

Insurance providers might be wary of covering diagnostic imaging given the limited data regarding its value in muscular dystrophies and its perceived overuse in other neurologic conditions. In addition, there are wide variations in coverage for MRI, even within a given region among individual payers. Thus we suggest that prior authorization be obtained for every case and, if need be, a peer-to-peer review also be done to explain the clinical rationale for using MRIs as a diagnostic tool in LGMDs (of note, Medicare does not perform preauthorization for most services).

\section{Genetic testing}

Genetic testing provides important diagnostic clarity for patients and neurologists and also helps avoid the costly and potential harm of treatment with immunosuppressive therapy. While this rationale is intuitive to most clinicians, payers may not perceive it similarly given the relatively high cost of testing up front with no current disease-modifying treatment. The LGMD and distal dystrophies guideline provides a Level B recommendation for clinicians to use a clinical approach to guide genetic diagnosis and testing. ${ }^{1}$ Thus a comprehensive neurologic history and examination should precede any genetic testing. In general, most third-party providers need 3 criteria to be fulfilled before they approve genetic testing. ${ }^{8}$ These include the following:

1. The patient displays clinical features of the disorder, or is at direct risk of inheriting the relevant mutation in question

2. The patient's care will be directly affected by information obtained from the test

3. A comprehensive evaluation including thorough patient and family history, physical examination, genetic counseling, and complete diagnostic evaluation using nongenetic testing does not lead to a definitive diagnosis

Many mutations causing LGMDs and distal dystrophies are relatively rare, and in some cases novel causative mutations may be revealed during the diagnostic evaluation. Many commercial and academic laboratories run diagnostic panels to evaluate for LGMDs, ${ }^{9}$ resulting in frequent issues with payment denial and sometimes high out-of-pocket patient costs for these tests. It is thus imperative that a prior authorization be obtained (if available from the payer) before these panels are sent out.

Emerging clinical genetic tools such as whole-exome sequencing or Next Gen sequencing present a growing payment challenge. ${ }^{10}$ There are wide variations in coverage, with some providers considering these tools investigational and thus not providing any coverage, ${ }^{11}$ while some may consider providing coverage on a case-by-case basis. There is hope that with rapid technological advancement the cost of this testing will come down further, which might make it more palatable for third-party payers. Alternative options for patients requiring expensive genetic testing include participation in research trials or approaching philanthropic organizations interested in particular diseases to help pay for the tests (e.g., the Jain Foundation may help with dysferlin gene testing).

\section{Physical therapy and other rehabilitation services}

The recent LGMD and distal dystrophies guideline could not offer any recommendation on the role of physical therapy and rehabilitation in LGMDs due to scarcity of rehabilitationrelated clinical trials. ${ }^{1}$ Patients and their family members may want to continue physical therapy even if it has had no outward benefit as they may perceive stopping therapy as giving up on the disease. It is important to set the expectation outright with the patient and family regarding the role of physical therapy and the potential limitations in its coverage.

Knowing the details of each patient's insurance plan is essential as many payers consider physical therapy medically necessary only when "this care is prescribed by a physician in order to significantly improve, develop or restore physical functions lost or impaired as a result of a 


\section{Careful selection of meaningful quality measures is especially important for progressive diseases such as LGMDs that do not at present have effective cures or disease- modifying therapies.}

disease, injury or surgical procedure." ${ }^{12}$ Restrictive policy language thus may result in denial of coverage. Even in those cases where physical therapy is approved, a 60-day limiting period may be applied (in a given calendar year or for the length of the plan).

Recently Centers for Medicare and Medicaid Services (CMS) approved expanded coverage of physical therapy services in those cases where it helps to maintain function. ${ }^{13}$ Thus careful and objective documentation of functional maintenance by the physician and physical therapists can provide longer duration of coverage to some of these patients. As a last resort, many patients and their families may choose to use their social security disability fund to continue physical therapy.

\section{Gene therapy, myostatin therapy, and other experimental treatment options}

Experimental therapies such as gene therapy or myostatin inhibition are generally not covered by third-party payers, but it is prudent to note that some payers might cover travel expenses in certain circumstances. ${ }^{14}$

\section{Multispecialty care}

The guideline provides a Level B recommendation that many patients with LGMD need periodic cardiorespiratory screening and treatment. ${ }^{1}$ Furthermore, these patients may need referral to other specialists, as many have multisystem involvement. Cardiomyopathy presents a source of potentially high morbidity complications in patients with LGMD, and neurologists who see patients with LGMD must be attuned to the need for appropriate cardiac surveillance even in the face of resistance from insurance carriers. Even asymptomatic carriers may need periodic cardiac screening. The guideline recommends periodic respiratory monitoring in those patients at high risk of ventilatory compromise (e.g., myofibrillar myopathy and LGMD 2I, Level B recommendation), and referral for sleep or pulmonary evaluation in all patients with LGMD who demonstrate clinical signs of insufficient sleep or ventilatory compromise. While more data would help to develop a comprehensive guideline on screening and treatment, denial of payment for these services is generally unlikely as long as appropriate $I C D$ codes are used and in cases where cardiorespiratory symptoms are present they be clearly documented. Further, there has been a clear precedent set with cardiorespiratory screening in Duchenne muscular dystrophy, which can be used to educate payers about the need for screening in many LGMDs. ${ }^{15}$ Careful documentation of mobility needs (if necessary, in conjunction with colleagues in physical medicine and physical therapy) is necessary to help patients navigate coverage of potentially costly powered mobility aids. Finally, when multispecialty care is required at a center outside the patient's coverage network (e.g., at an academic medical center), the patient and primary care provider may need to request an exemption from the insurer to provide this specialized and often cost-effective care.

\section{Value-based payment for care of patients with LGMD}

CMS and other payers are steadily moving toward payment models that reward quality of care rather than strictly volume of services. As a result, physicians and specialty societies should be actively involved in identification and production of meaningful clinical quality measures. Careful selection 
of meaningful quality measures is especially important for progressive diseases such as LGMDs that do not at present have effective cures or disease-modifying therapies. ${ }^{16}$ The AAN is currently developing a quality measure set for muscular dystrophies. Eventually, the long-term trend toward value-based payment will require neurologists who take care of patients with LGMD to carefully observe and document clinical best practices to assure that optimal care is delivered to these patients, reasonable payment is received, and therefore patient access to care is preserved.

\section{CONCLUSION}

The care of patients with LGMDs and distal dystrophies presents a challenging combination of diagnostic complexity and supportive, anticipatory management. From a payment perspective, the costs associated with evaluation and management of these patients may require discussions with third-party payers to explain the rationale and supporting evidence behind the clinical recommendations. In the future, clinicians will need to be mindful of value-based payment methodologies in caring for patients with LGMD and distal dystrophies, and neurologists should be active in the creation of meaningful and reasonable quality measures.

\section{REFERENCES}

1. Narayanaswami P, Weiss M, Selcen D, et al. Evidence-based guideline summary: diagnosis and treatment of limb-girdle and distal dystrophies: report of the guideline development subcommittee of the American Academy of Neurology and the practice issues review panel of the American Association of Neuromuscular \& Electrodiagnostic Medicine. Neurology 2014;83:1453-1463.

2. Bushby KM, Beckmann JS. The limb-girdle muscular dystrophies: proposal for a new nomenclature. Neuromuscul Disord 1995;5:337-343.

3. Bushby KM. Diagnostic criteria for the limb-girdle muscular dystrophies: report of the ENMC Consortium on Limb-Girdle Dystrophies. Neuromuscul Disord 1995;5:71-74.

4. 2012 ICD-9-CM Diagnosis Code 359: Muscular Dystrophies and Other Myopathies. Available at: http://www.icd9data.com/2012/Volume1/320-389/350-359/359/359.htm. Accessed July 22, 2015.

5. 2015 ICD-10-CM Diagnosis Code G71.0: Muscular Dystrophy. Available at: http://www.icd10data. com/ICD10CM/Codes/G00-G99/G70-G73/G71-/G71.0. Accessed July 22, 2015.

6. Finanger EL, Russman B, Forbes SC, Rooney WD, Walter GA, Vandenborne K. Use of skeletal muscle MRI in diagnosis and monitoring disease progression in Duchenne muscular dystrophy. Phys Med Rehabil Clin N Am 2012;23:1-10.

7. Faridian-Aragh N, Wagner KR, Leung DG, Carrino JA. Magnetic resonance imaging phenotyping of Becker muscular dystrophy. Muscle Nerve 2014;50:962-967.

8. Aetna Clinical Policy Bulletin for Genetic Testing. Available at: http://www.aetna.com/cpb/medical/ data/100_199/0140.html. Accessed July 282015.

9. Limb girdle muscular dystrophy advanced evaluation. Available at: http://athenadiagnostics.com/viewfull-catalog/l/limb-girdle-muscular-dystrophy-advanced-evaluation. Accessed July 272015.

10. Thompson Reuters. As sequencing moves into clinical use, insurers balk. Available at: http://www. reuters.com/article/2014/06/19/us-health-sequencing-insight-idUSKBN0EU16S20140619. Accessed July 22, 2015.

11. Blue Cross Blue Shield Special Report. Exome sequencing for clinical diagnosis of patients with suspected genetic disorders. Available at: http://www.bcbs.com/blueresources/tec/vols/28/28_03.pdf. Accessed July 22, 2015.

12. Aetna Physical Therapy Services Policy Number 0325. Available at: http://www.aetna.com/cpb/ medical/data/300_399/0325.html. Accessed July 22, 2015.

13. MLN Matters Number MM458: Manual updates to clarify skilled nursing facility (SNF), inpatient rehabilitation facility (IRF), home health $(\mathrm{HH})$, and outpatient (OPT) coverage pursuant to Jimmo vs. Sebelius. Available at: http://www.cms.gov/Outreach-and-Education/Medicare-Learning-NetworkMLN/MLNMattersArticles/Downloads/MM8458.pdf. Accessed July 22, 2015.

14. Health and Human Services. What expenses are covered? Available at: http://www.mass.gov/eohhs/ gov/departments/dph/programs/family-health/cicrf/what-expenses-are-covered.html. Accessed July 28, 2015.

15. Muscular Dystrophy Association. Help with health care and equipment costs. Available at: http:// mda.org/publications/mda-als-caregivers-guide/chapter-7/help_with_costs. Accessed July 22, 2015.

16. Miller RG, Brooks BR, Swain-Eng RJ, et al. Quality improvement in neurology: amyotrophic lateral sclerosis quality measures: report of the Quality Measurement and Reporting Subcommittee of the American Academy of Neurology. Neurology 2013;81:2136-2140. 


\section{ACKNOWLEDGMENT}

AAN Payment Policy Subcommittee for their support in identifying the need for this paper and also for their review of an early draft of the manuscript. Lead AAN LGMD Guideline author Pushpa Narayanaswami, MBBS, DM, FAAN for her critical review of the manuscript.

\section{AUTHOR CONTRIBUTIONS}

Raghav Govindarajan: study concept and design, analysis and interpretation, critical revision of the manuscript for important intellectual content. Katie Shepard: study concept and design, critical revision of the manuscript for important intellectual content. Lyell K. Jones: study concept and design, critical revision of the manuscript for important intellectual content.

\section{STUDY FUNDING}

No targeted funding reported.

\section{DISCLOSURES}

R. Govindarajan reports no disclosures. K.M. Shepard is a full-time employee of the American Academy of Neurology. L.K. Jones, Jr, receives publishing royalties for Mayo Clinic Neurology Board Review (Oxford University Press, 2015). Full disclosure form information provided by the authors is available with the full text of this article at Neurology.org/cp.

\section{Related articles from AAN physician and patient resources}

\section{Neurology ${ }^{\circledR} \quad$ Neurology.org}

Clinical and genetic spectrum in limb-girdle muscular dystrophy type $2 \mathrm{E}$ April 28, 2015;84:1772-1781.

Evidence-based guideline summary: Diagnosis and treatment of limb-girdle and distal dystrophies

Report of the Guideline Development Subcommittee of the American Academy of Neurology and the Practice Issues Review Panel of the American Association of Neuromuscular \& Electrodiagnostic Medicine

October 14, 2014;83:1453-1463.

\section{Continuum $^{\circledR}$ - ContinuumJournal.com}

The Muscular Dystrophies

December 2013;19:1535-1570.

Genetic Evaluation of Inherited Muscle Diseases

April 2011;17:280-293.

\section{Neurology Now ${ }^{\circledR}$ - Neurologynow.com}

Guidelines: Guiding the Way: New medical guidelines weigh in on genetic testing, exercise, and more for people with muscular dystrophy

February/March 2015;11:14-15.

Muscular Dystrophy Treatments

August/September 2011;7:39.

\section{Neurology Today ${ }^{\circledR}$}

- Neurotodayonline.com

AAN Issues Guideline on Diagnosing, Treating Limb-Girdle Muscular Dystrophies

October 16, 2014;14:1, 10-14. 


\title{
Neurology ${ }^{\circ}$ Clinical Practice
}

\author{
Diagnosis and treatment of limb-girdle and distal dystrophies: Payment policy \\ perspectives \\ Raghav Govindarajan, Katie M. Shepard and Lyell K. Jones, Jr
}

Neurol Clin Pract 2015;5;454-459 Published Online before print September 17, 2015

DOI 10.1212/CPJ.0000000000000188

This information is current as of September 17, 2015

$\begin{array}{ll}\begin{array}{l}\text { Updated Information \& } \\ \text { Services }\end{array} & \begin{array}{l}\text { including high resolution figures, can be found at: } \\ \text { http://cp.neurology.org/content/5/5/454.full.html }\end{array} \\ \text { References } & \begin{array}{l}\text { This article cites } 6 \text { articles, } 0 \text { of which you can access for free at: } \\ \text { http://cp.neurology.org/content/5/5/454.full.html\#\#ref-list-1 }\end{array} \\ \text { Permissions \& Licensing } & \begin{array}{l}\text { Information about reproducing this article in parts (figures,tables) or in } \\ \text { its entirety can be found online at: } \\ \text { http://cp.neurology.org/misc/about.xhtml\#permissions }\end{array} \\ \text { Reprints } & \begin{array}{l}\text { Information about ordering reprints can be found online: } \\ \text { http://cp.neurology.org/misc/addir.xhtml\#reprintsus }\end{array}\end{array}$

Neurol Clin Pract is an official journal of the American Academy of Neurology. Published continuously since 2011, it is now a bimonthly with 6 issues per year. Copyright $\odot 2015$ American Academy of Neurology. All rights reserved. Print ISSN: 2163-0402. Online ISSN: 2163-0933.

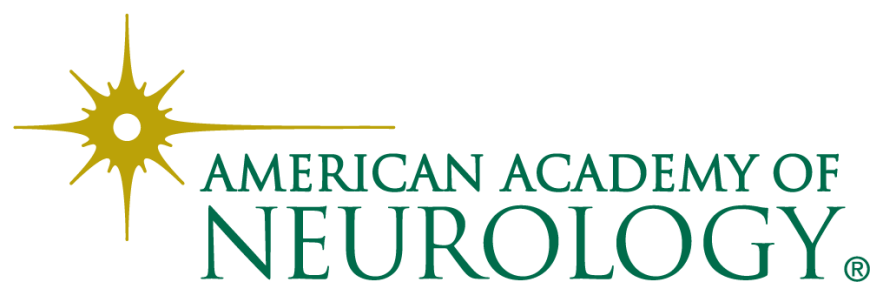

